\title{
Reformas y crecimiento en América Latina
}

\section{Andrea C. Bandeira}

Maestra en Economía,

Candidata al doctorado en el Instituto de Pesquisa Económica,

Universidad de São Paulo

camara@gvmail.br

\section{Fernando Garcia}

Profesor Adjunto de la

Escuela de Administración

de Empresas de São Paulo,

Fundación Getulio Vargas

fgarcia@fgvsp.br
En este artículo se analizan los efectos de las reformas económicas efectuadas por los países latinoamericanos a partir de la segunda mitad del decenio de 1980. Para incluir los índices de reformas entre los elementos determinantes del producto interno bruto per cápita, conforme a la visión de los modelos neoclásicos de crecimiento, se partió de la interpretación del carácter institucional de dichas reformas. El análisis econométrico, elaborado sobre la base de un conjunto de 17 países latinoamericanos y referido al período 1970-1995, reveló que las cinco áreas de reforma estudiadas tuvieron efectos significativos en el PIB. A partir del análisis empírico, se puede concluir que: i) el impacto general de las reformas en el PIB per cápita fue positivo, como ya lo habían indicado otros estudios; ii) el principal mecanismo mediante el cual las reformas elevaron los ingresos per cápita fue el efecto positivo que ellas tuvieron en la productividad del factor capital, y iii) la acumulación de capital también reaccionó positivamente ante las reformas. 
I

\section{Introducción}

En la primera mitad del decenio de 1990 se observa una recuperación de las tasas de crecimiento de los países latinoamericanos, en comparación con el crecimiento registrado durante el decenio anterior. Entre los factores que se citan como causas de dicha recuperación se destacan los planes de estabilización que tuvieron buenos resultados y la existencia de condiciones internacionales más favorables, vinculadas al aumento de la liquidez y a la reducción de las tasas de interés internacionales; a la reanudación de las corrientes de capital externo hacia la región, y a la expansión económica estadounidense, principalmente a partir de 1992. Según una serie de trabajos relativamente recientes, las reformas económicas de las décadas de 1980 y 1990 contribuyeron en parte al crecimiento de la región. Entre ellos cabe destacar los trabajos de Easterly, Loayza y Montiel (1997), Fernández-Arias y Montiel (1997), Barrera y Lora (1997), Burki y Perry (1997) y Fajnzylber y Lederman (1999), así como el proyecto de investigación "Crecimiento, empleo y equidad: América Latina en el decenio de 1990", emprendido por la CEPAL, que abarca una serie de estudios relacionados con el tema, como los de Morley, Machado y Pettinato (1999), Hofman (2000), Paunovic (2000) y Escaith y Morley (2000).

Un análisis preliminar del desempeño de las economías latinoamericanas durante el período de reforma revela que las tasas medias de crecimiento fueron superiores a las registradas en el decenio de 1980, aunque inferiores a las correspondientes al período comprendido entre 1950 y 1980 , en el cual prevaleció el "antiguo" modelo de desarrollo. Sobre la base de metodologías muy similares, Easterly, Loayza y Montiel (1997) y Fernández-Arias y Montiel (1997) examinan el tema de las reformas y llegan a conclusiones muy parecidas: en términos de crecimiento, la respuesta a las reformas económicas fue satisfactoria y acorde con lo esperado, si se toma en cuenta la experiencia internacional al respecto. Barrera y Lora (1997) siguen la misma línea. Muestran que las reformas introducidas en los años ochenta aumentaron el crecimiento a largo plazo en 1.9 puntos porcentuales en relación con el registrado con anterioridad, debido sobre todo a sus efectos en la productividad y la inversión. La productividad total de la economía aumentó
$1.7 \%$ en el período examinado, mientras la tasa media de inversión de la región registraba un crecimiento de igual magnitud. ${ }^{1}$

Fajnzylber y Lederman (1999), aplicando la metodología de contabilidad del crecimiento, tratan de medir los efectos de las reformas económicas en la productividad total de los factores de 18 economías latinoamericanas. La principal conclusión de su trabajo es que, en promedio, el crecimiento de la productividad fue más acelerado durante los períodos de reforma económica.

En lo que respecta al proyecto de investigación de la CEPAL mencionado más atrás, Paunovic (2000) y Hofman (2000) examinan la relación entre las reformas y el desempeño económico de América Latina durante el decenio de 1990. El primero de estos autores trabaja sobre la base de conceptos de economía política para analizar las razones por las cuales los países de la región se dividen en subgrupos de acuerdo con su desempeño en términos de tasas de crecimiento, así como la relación entre dicha segmentación y el grado de avance de las reformas en cada país. Según este autor, los países que introdujeron más reformas y que lograron estabilizar efectivamente sus economías fueron los que registraron las tasas más altas de crecimiento en el decenio de 1990. Hofman (2000), al examinar el crecimiento económico de un conjunto de países de la región, hace hincapié en las diferencias que se observan en la tasa de crecimiento del producto entre las distintas economías estudiadas y a lo largo del tiempo. Analiza el desempeño de esa muestra de países a nivel agregado y en términos de crecimiento económico, acumulación de factores y diferentes formas de medir la productividad. Divide el período comprendido entre 1950 y 1998 en subperíodos, tomando como referencia la crisis de la deuda y la recuperación económica posterior. A partir de esta división, y aplicando una metodología de contabilidad del crecimiento, Hofman llega a algunas conclusiones respecto de cada país. En términos generales, durante el período de reformas los países estudiados mostraron una recu-

\footnotetext{
${ }^{1}$ Burki y Perry (1997) compilaron los resultados de los tres estudios mencionados en el párrafo.
} 
peración respecto del decenio de 1980 (período de crisis), pero no lograron igualar, considerando ciertas variables, su desempeño del período comprendido entre 1950 y 1980.

En el artículo de Escaith y Morley (2000) se evalúan los efectos que las cinco áreas de reforma -apertura comercial, liberalización de la cuenta de capital, privatización y reformas financiera y tributaria-, las mismas que se analizan en el presente artículo, tuvieron en la tasa de crecimiento económico de 17 economías latinoamericanas en el período comprendido entre 1970 y 1996. Sobre la base de un modelo estadístico, en el cual se tiene en cuenta un grupo numeroso de variables de control, ${ }^{2}$ los autores llegan a la conclusión de que las reformas, consideradas en conjunto, no produjeron un efecto directo en el crecimiento económico de la región, lo que suponen se debe a los efectos compensatorios de las diversas reformas. Solamente la reforma tributaria y la liberalización de la cuenta de capital tuvieron un impacto significativo en el desempeño de los países de la región. Sin embargo, los autores no excluyen la posibilidad de que las reformas hayan repercutido de manera indirecta en el crecimiento de América Latina en el período estudiado, a través de factores como la inversión y la estabilidad macroeconómica.

El impacto positivo de las reformas en el crecimiento económico de los países latinoamericanos, defendido por los estudios citados, fue lo que motivó la presente investigación. A diferencia de algunos de esos trabajos, lo que interesa en este caso no es solamente analizar los efectos en el crecimiento; en ese aspecto parece existir consenso en la bibliografía en cuanto a que el impacto general de las reformas fue significativo y positivo. Lo que aquí se propone es investigar cómo se produjo ese efecto y a través de qué mecanismos, es decir, considerando las denominadas fuentes del crecimiento: la acumulación y la productividad de los factores.

Cabe señalar que el presente artículo parte de un enfoque metodológico diferente al adoptado en la mayor parte de la bibliografía existente sobre el tema. Según Temple (1999), el enfoque más común se sustenta en regresiones de crecimiento ad hoc o informales. Los estudios recientes que aplican este esquema se basan fundamentalmente en el trabajo de Barro

\footnotetext{
${ }^{2}$ Entre estas variables de control se destacan los indicadores relativos a la conducción de la política macroeconómica y al dinamismo de la economía internacional.
}

(1991), y vinculan la tasa de crecimiento del producto a un conjunto de variables consideradas relevantes desde el punto de vista empírico o teórico. Sin embargo, la especificación que se debe calcular no se deriva directamente de modelos teóricos, y es por eso que estas regresiones se denominan informales. Las variables consideradas pueden dividirse en dos grupos. El primero corresponde al nivel inicial de las denominadas variables de estado: acervo de capital físico y humano, este último en forma de indicadores asociados al nivel de escolaridad. El segundo grupo está formado por variables de control, como la participación de los gastos de consumo del gobierno en el PIB, la inversión interna como proporción del PIB, el margen de ganancia del mercado de cambios paralelo, el grado de inestabilidad política y la variación de la relación de precios del intercambio, entre otras.

En cambio, el presente artículo parte de la premisa de que una base teórica sólida y un análisis empírico formal pueden ayudar en la investigación de los impactos de las reformas. Y ello por varios motivos. El que tiene más importancia para los fines del presente artículo es el que una formulación teórica permite elaborar y verificar distintas hipótesis sobre los mecanismos por los cuales las reformas afectaron al desempeño de la región. ${ }^{3}$

Además de esta introducción (sección I), el artículo tiene cuatro secciones en las que se analiza la relación existente entre las reformas económicas, los cambios institucionales, el crecimiento económico y lo que lo determina (acumulación de factores y productividad). En la sección II se resumen las principales medidas de reforma adoptadas en América Latina - apertura comercial, reformas financiera y tributaria, privatización, liberalización de la cuenta de capital y reformas de la seguridad social y laboral—, y se analiza en qué medida las reformas pueden considerarse cambios de carácter institucional. Para ello se toma como referencia teórica el enfoque desde el derecho y la economía de Hirsch (1988).

\footnotetext{
${ }^{3}$ Además, al utilizar un modelo teórico específico, se puede hacer una comparación con otros enfoques teóricos, en particular con el modelo establecido en el área de crecimiento económico. En consecuencia, los propios resultados econométricos obtenidos a partir de modelos empíricos formales también pueden ser comparados con los de otros trabajos, como los presentados por Campos y Nugent (1998) y por Piedrahita (1998). Este enfoque también permite identificar y evaluar el sentido económico de las variables ficticias y de los coeficientes estimados por los modelos de datos de panel, como propone, por ejemplo, Islam (1995).
} 
En la sección III se expone brevemente el modelo de crecimiento económico que fundamenta la parte empírica del artículo, que es la teoría del crecimiento de Solow, una vez incorporados los aportes de Mankiw, Romer y Weil (1992), de Hall y Jones (1996 y 1999) y de Jones (2000). Posteriormente se analizan las formas de incorporar variables de cambios institucionales en el esquema de los modelos neoclásicos de crecimiento, una de las cuales corresponde al concepto de infraestructura social, desarrollado por Hall y Jones (1996 y 1999) y formalizado por Jones (2000), en tanto la otra hace referencia al trabajo de Garcia y otros (1999). Sobre la base de este modelo teórico de crecimiento económico, en la sec- ción IV se analiza la relación empírica entre los índices de reformas, elaborados por Morley, Machado y Pettinato (1999), la productividad de los factores y la acumulación de capital. En dicho análisis se investigan los impactos de las reformas sobre el producto per cápita, el crecimiento económico y la acumulación de factores de los países latinoamericanos en los dos últimos decenios, lo que permite identificar el principal mecanismo por el cual las reformas económicas generaron crecimiento: el aumento de la productividad del capital. La sección V incluye unas breves consideraciones finales, y, por último, en un apéndice se presentan las estimaciones de la ecuación de convergencia.

\section{II}

\section{Reformas económicas y cambios institucionales}

Desde las décadas de 1940 y 1950, el panorama económico latinoamericano se ha caracterizado por un fuerte proteccionismo y por la presencia del Estado en diversas actividades y sectores económicos. A partir de la segunda mitad del decenio de 1980, esa estructura comenzó a ceder espacio a una nueva estrategia que, entre otros aspectos, daba prioridad a la liberalización de los mercados, una orientación hacia afuera (en el sentido de estimular el comercio y las exportaciones), y una menor intervención del Estado. Este conjunto de políticas tuvo una evolución gradual en la región. El proceso ya se había iniciado en la década de 1970, en medio de la primera crisis del petróleo. En ese período, las reformas abarcaron un número de áreas menor que en los decenios siguientes y estuvieron restringidas a un conjunto reducido de países. A pesar de sus avances en muchos frentes, a comienzos de 1980 la mayoría de ellas sufrieron un retroceso a raíz de la crisis de la deuda. Sólo en los años subsiguientes, principalmente a partir de 1985, comenzaron a adquirir un nuevo ímpetu y a abarcar un mayor número de economías. Luego, a fines del decenio de 1980 y comienzos del de 1990, el proceso se consolidó en toda la región, y las medidas dejaron de confundirse con políticas de estabilización para empezar a ser consideradas reformas estructurales.

El consenso en torno a la necesidad de llevar a cabo reformas de este tipo se basó en la percepción de que la "antigua estrategia" de desarrollo era incapaz de garantizar el crecimiento económico, principalmente debido a los desequilibrios, distorsiones e ineficiencias generados por las políticas adoptadas a partir de los decenios de 1940 y $1950 .{ }^{4}$ Según el consenso que surgió tras la crisis de la deuda, el fuerte proteccionismo, el dirigismo estatal y la excesiva regulación de los mercados habían reducido la eficiencia económica, restringido el crecimiento de la productividad, determinado una mala asignación de los recursos y limitado la actuación del sector privado. Esto se debía a que en las decisiones de inversión la acción del Estado pesaba mucho más que los criterios de eficiencia. Según Morley, Machado y Pettinato (1999), los distintos países latinoamericanos se fueron orientando gradualmente hacia su visión particular de la forma en que debía funcionar la economía y del papel que debía desempeñar el gobierno.

Considerando la evolución de este proceso desde 1985 hasta mediados del decenio de 1990, la amplia bibliografía sobre el tema identifica siete áreas principales de reforma: comercial, financiera, tributaria, liberalización de la cuenta de capital, privatización, se-

\footnotetext{
${ }^{4}$ Con respecto a los objetivos específicos y detalles técnicos de las distintas áreas de reforma, véase Edwards (1995), Lora (1997), BID (1997), Morley, Machado y Pettinato (1999) y Bandeira (2000).
} 
guridad social y mercado de trabajo. Por el alcance de las cinco primeras áreas de reforma y el número de países abarcados, se las conoció con el nombre de reformas de primera generación. Las dos últimas - seguridad social y mercado de trabajo, todavía incipientes en la mayor parte de los países latinoamericanospasarían a integrar, junto con otro grupo de medidas, ${ }^{5}$ las denominadas reformas económicas de segunda generación.

El primer intento de cuantificar las reformas latinoamericanas puede atribuirse a Lora (1997), quien desarrolló un índice de políticas estructurales para un conjunto de 18 economías. El período analizado va de 1985 a 1995. Este índice es el promedio simple de otros cinco índices, cada uno de los cuales refleja la evolución en las áreas siguientes: comercial, tributaria, financiera, privatización y mercado de trabajo. Morley,
Machado y Pettinato (1999) elaboraron, para el período 1970-1995, otro índice de reforma correspondiente a una muestra de 17 países de América Latina. ${ }^{6} \mathrm{Al}$ igual que el índice construido por Lora, éste estaba compuesto de otros cinco: comercial, financiero, tributario, de liberalización de la cuenta de capital y de privatización. ${ }^{7} \mathrm{El}$ gráfico 1 muestra el comportamiento de los seis índices, siendo el índice general el formado por el promedio simple de los índices correspondientes a cada reforma. Dichos índices dan un panorama de la evolución y el alcance de estas reformas entre 1970 y 1995, así como de las distintas trayectorias en las cinco áreas analizadas.

Sin perjuicio de que cada área de reforma haya tenido características específicas de importancia, tan relevantes como las diferencias existentes entre los países, el objetivo de esta sección es desarrollar un

GRAFICO 1

Indice de reformas y sus componentes

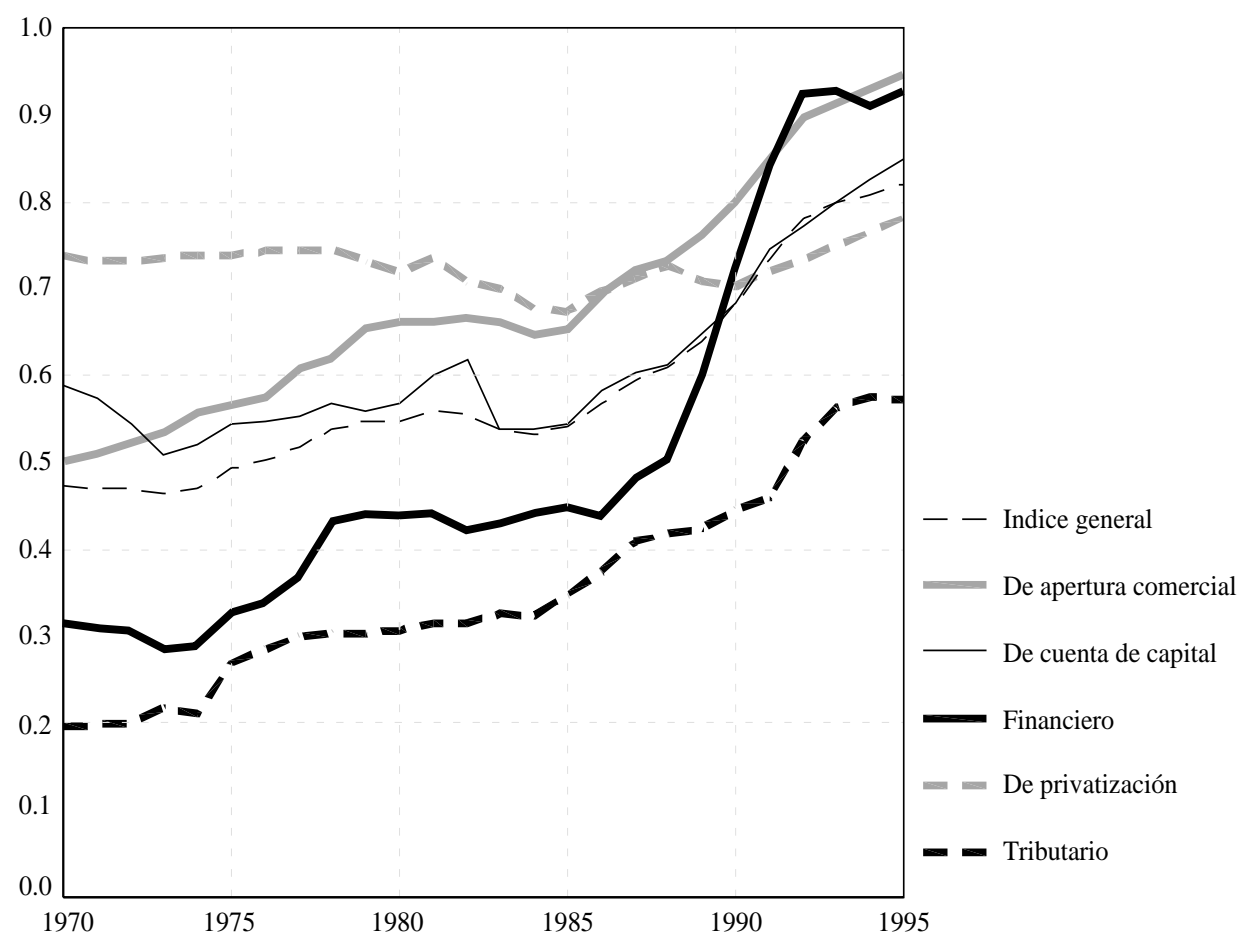

Fuente: Morley, Machado y Pettinato (1999).

5 Destacando la reforma del Estado, principalmente de su parte administrativa, y de las instituciones, como el poder judicial y el sistema de educación.

${ }^{6}$ Argentina, Bolivia, Brasil, Chile, Colombia, Costa Rica, Ecuador, El Salvador, Guatemala, Honduras, Jamaica, México, Paraguay, Perú, República Dominicana, Uruguay y Venezuela.

\footnotetext{
${ }^{7}$ Los autores no incluyeron la reforma de la seguridad social y del mercado de trabajo porque éstas eran aún incipientes en la mayoría de los países durante el período analizado. Para elaborar estos índices, solamente se consideraron variables de política bajo el control del gobierno, y se normalizaron los índices dentro del intervalo 0 a 1 , asignándose el valor 1 a una estructura exenta de toda distorsión.
} 
argumento general que califique ese proceso de transformación de las economías latinoamericanas. ${ }^{8}$ En términos generales, la bibliografía relativa a las reformas en América Latina destaca solamente su índole económica: sus efectos en los precios relativos. En este artículo se sostiene que las reformas no representan solamente un cambio económico, sino también uno institucional.

A partir de los decenios de 1940 y 1950, el Estado fue asumiendo gradualmente un papel crucial en las economías latinoamericanas, con el fin de llevar a cabo el proceso de industrialización basado en la sustitución de las importaciones. Sus acciones tuvieron repercusiones económicas considerables. Puede decirse que el funcionamiento de los distintos mercados y la interacción entre ellos estuvieron condicionados por toda la estructura creada en el período anterior al decenio de 1980. Ese entorno, junto con favorecer el proceso de industrialización en muchos países, generó distorsiones de diversa índole, principalmente en el sistema de precios relativos, con la consiguiente ineficiencia en la asignación de recursos, baja productividad y pérdida de bienestar. En tal sentido, las reformas iniciadas en el decenio de 1980, al concretar la reducción de los controles sobre los distintos mercados, representaron cambios económicos significativos.

Por otra parte, puede decirse también que las reformas engendraron un importante proceso de cambios institucionales. Esto porque con ellas se alteraron la "apropiabilidad" de los derechos, los costos de transacción, la estructura de la rentabilidad de las inversiones, el entorno en que se realiza el intercambio y se celebran los contratos entre los agentes económicos, además de las normas que rigen el derecho de propiedad. El modo de funcionamiento de las economías y el papel desempeñado por el Estado constituyen el punto de partida para el debate sobre el carácter institucional de las reformas. La base de dicho análisis es un campo relativamente nuevo de las ciencias económicas: la aplicación de la microeconomía al campo del derecho. La argumentación que se expone a continuación se fundamenta en dos importantes estudios sobre este tema: Hirsch (1988) y Cooter y Ulen (1988).

Al tiempo que las estructuras de precios de las economías se veían afectadas por la modalidad de desarrollo de los países latinoamericanos, la capacidad

\footnotetext{
${ }^{8}$ Bandeira (2000) compila datos detallados sobre las distintas áreas de reforma y sobre las experiencias nacionales, y presenta una reseña de los principales trabajos sobre el tema.
}

de los agentes económicos de apropiarse de sus derechos puede haberse visto igualmente condicionada durante los decenios anteriores. Esto finalmente dio lugar a lo que se ha definido como "apropiabilidad imperfecta" de los derechos. Este concepto está directamente relacionado con la idea de externalidad, que surge cuando el consumo o la producción de un agente económico afecta a la utilidad de otro, sin que exista una adecuada compensación de mercado. Esto equivale a decir que las funciones de los individuos o de las empresas son interdependientes. Según Cooter y Ulen (1988), la esencia del problema creado por la existencia de externalidades radica en que la maximización de las utilidades no conduce a soluciones eficientes en la economía. Los que toman decisiones racionales, centrados en su propio interés, por lo general no tienen en cuenta el impacto que ellas pueden tener en las utilidades o la producción de otros. De aquí que tales efectos se produzcan sin el consentimiento de esos otros y sin la debida compensación.

¿Por qué ocurre esto? Una de las razones principales es justamente la apropiación imperfecta de los derechos. Recurriendo nuevamente a los elementos presentados por Hirsch (1988), esa apropiación imperfecta se produce cuando un agente económico cualquiera no logra apropiarse totalmente del valor marginal de los beneficios que genera, o no puede evitar el costo impuesto por otro agente en el caso de una externalidad negativa. De esa manera, y aun cuando desde el punto de vista económico quien ejerce el derecho pueda ser capaz de tomar decisiones sobre la utilización de sus recursos y reclamar los beneficios que éstos generen, existen otros factores que pueden determinar que ese derecho no esté garantizado. En tal sentido, así como los derechos contribuyen a definir el conjunto de oportunidades y el comportamiento de los agentes - $-\mathrm{y}$, por ende, los resultados de sus acciones y elecciones-, el grado de protección de esos derechos (grado de cumplimiento) en definitiva también moldea esos mismos elementos.

Existen razones y factores de orden ético e institucional que posiblemente contribuyen a reducir la apropiabilidad de los derechos. Cuando esto sucede, la validez del denominado principio de exclusión pasa a ser incierta. Según la definición de Musgrave (1959), este principio establece que las personas están excluidas del usufructo de una determinada mercadería, a menos que estén dispuestas a pagar a su propietario el precio establecido. Este principio puede extenderse a la utilización de factores productivos y al beneficio y las ganancias que de éstos se deriven. Si fuera posible 
consumir una determinada mercadería de mutuo acuerdo, sin la debida compensación, se estaría violando el principio. Si el costo asociado a la garantía de exclusividad fuera elevado, es decir, exigiera recursos considerables, la validez del principio pasaría a ser igualmente incierta y la apropiabilidad de los derechos sería imperfecta. En estas circunstancias, cuando se realiza el intercambio o los factores se emplean en actividades productivas, los agentes acaban por absorber efectivamente el costo de excluir del consumo (o de los beneficios de la actividad) a otros agentes. Es decir, que en el caso mencionado los costos de transacción serían más elevados, con tres consecuencias importantes: i) la reducción del número de transacciones dentro de la economía; ii) la interferencia en la existencia de mercados, y iii) la perpetuación de externalidades.

Por lo tanto, la apropiabilidad de los derechos condiciona en gran medida las decisiones de los agentes económicos. La garantía y la satisfacción de los derechos de propiedad estimulan el uso eficiente de los recursos dentro del sistema capitalista. Dado el marco jurídico y regulatorio - las instituciones de derecho-, los agentes confían en mayor o menor grado en la rentabilidad correspondiente al uso de su propiedad (Hirsch, 1988, p. 25). Por lo tanto, puede afirmarse que tanto la acumulación de factores como la evolución de su productividad dependen del desarrollo institucional, cuyo aspecto central es el grado de apropiabilidad de los derechos. Esto significa que el desempeño en términos de crecimiento económico y bienestar social de un determinado país resultan en última instancia afectados por la estructura institucional existente.

Esa conclusión es crucial para comprender la naturaleza institucional de las reformas. En los países latinoamericanos, en cada una de las áreas y mercados en que ha intervenido el Estado, es posible identificar factores que terminaron reduciendo la capacidad de los agentes de apropiarse de sus derechos. ${ }^{9}$ Un factor común a casi todas las áreas fue el alto grado de discrecionalidad asociado a las políticas y decisiones de los gobiernos. Es evidente que toda política pública tiene un componente arbitrario, que puede estar vinculado con la posición política o ideológica de los gobernantes. Sin embargo, en el caso de los países de América Latina, se puede afirmar que dicho componente tuvo un peso mayor, principalmente por la naturaleza del proceso de industrialización, dirigido por el Estado. Cabe señalar que, a partir del decenio de 1970, la discrecionalidad se incrementó como consecuencia del aumento de los desequilibrios interno y externo. En realidad, este componente siempre estuvo más asociado a los planes de ajuste implementados por los diversos países en respuesta a los desequilibrios. Es decir, tanto los aspectos conyunturales como aquellos propios del modelo de desarrollo elegido por la mayoría de los países de la región reforzaron el componente arbitrario inherente a la formulación y la implementación de políticas públicas. Por lo tanto, el horizonte y los resultados esperados por los agentes económicos se vieron muchas veces afectados por inesperados cambios de rumbo, resultantes de decisiones arbitrarias de los gobiernos. ${ }^{10}$

Esta lectura del modelo económico anterior y de la índole de las reformas económicas en América Latina, que difiere de la que prevalece en la bibliografía sobre el tema, constituye un argumento crucial del presente artículo. Ella permite evaluar los mecanismos mediante los cuales se procesó el efecto de las reformas, sobre la base de un esquema teórico que combina los fundamentos neoclásicos del crecimiento con aspectos teóricos de la Nueva Economía Institucional.

\footnotetext{
${ }^{9}$ Debe tenerse en cuenta que la estructura institucional de un país difícilmente garantizará la apropiación perfecta de los derechos. La idea que se expone en este artículo es que las circunstancias propias de América Latina han determinado que exista en ésta, en relación con otros países o regiones, un menor grado de apropiabilidad de los derechos, lo que afecta a la acumulación, la productividad y el crecimiento económico.
}

10 Bandeira (2000) analiza en forma detallada de qué manera las reformas económicas latinoamericanas trataron, directa o indirectamente, de aumentar la capacidad de los agentes de apropiarse de sus derechos. 


\section{III}

\section{Cambios institucionales, productividad de los factores y crecimiento}

La influencia de las variables institucionales en el desempeño económico, principalmente en lo que respecta al crecimiento y la desigualdad, ha sido analizada en una serie de trabajos e investigaciones recientes. Uno de los fundamentos principales de esa línea de trabajo deriva de los conceptos desarrollados por Douglass North en el ámbito de la Nueva Economía Institucional. En términos más específicos, existen estudios que analizan el papel de las instituciones para explicar las causas del crecimiento económico, destacando los efectos que han tenido los cambios institucionales en la acumulación y la productividad de los factores. Los trabajos de Hall y Jones (1996 y 1999), Jones (2000) y Garcia y otros (1999) siguen esa línea.

Los artículos de Hall y Jones desarrollan el concepto de infraestructura con el fin de explicar las diferencias del producto por trabajador observadas entre las distintas economías. Para ello, los autores parten de un análisis basado en una función de producción agregada y en el concepto de acumulación de factores. Según ese análisis, las diferencias de nivel del producto por trabajador existentes entre los países pueden atribuirse a las diferencias de capital físico, de capital humano y de productividad total de los factores; es decir, a los denominados elementos determinantes del crecimiento, que estarían asociados fundamentalmente a la infraestructura social de las economías. Hall y Jones definen la infraestructura social como las instituciones y las políticas del gobierno (o públicas) que determinan el entorno en el cual las personas acumulan habilidades y las empresas acumulan capital, invierten en tecnología y generan producto. Según estos autores, una estructura que incentive las actividades productivas y fomente la acumulación de capital, la adquisición de habilidades, la invención y la transferencia de tecnología, conduciría a niveles más altos de producto por trabajador.

Hall y Jones (1996 y 1999) parten de un esquema basado en una función de producción agregada del tipo Cobb-Douglas, en la que el producto de cada país $Y$ está determinado por el acervo de capital físico $K$, de capital humano $H$ y de conocimiento $A$, de modo que $Y_{i}=K_{i}^{\alpha}\left(A_{i} H_{i}\right)^{1-\alpha}$. Replantean la función de la siguiente manera:

$$
y_{i}=\left(\frac{K_{i}}{Y_{i}}\right)^{\alpha / 1-\alpha} h_{i} A_{i}
$$

donde $y=(Y / L)$ y $h=(H / L)$. Esta ecuación permite descomponer las diferencias del producto por trabajador entre los distintos países en tres partes, que se refieren a la relación capital-producto, la educación y la productividad. A partir de este esquema, los autores hacen una investigación empírica de la relación entre el nivel de producto por trabajador y un conjunto de variables que actúan como variable sustitutiva (proxy) de la infraestructura social, habida cuenta de que no existe un grupo de variables que represente directamente este concepto.

Jones (2000) desarrolla en forma teórica la idea de la infraestructura social, y propone una modificación del modelo de crecimiento neoclásico. La función de producción mencionada anteriormente se replantea de la siguiente manera:

$Y=I K^{\alpha}(h L)^{1-\alpha}$, con $H_{i}=h_{i} L_{i}$ y $h_{i}=e^{\phi . u}$

donde $I$ representa la influencia de la infraestructura de la economía en la productividad total de los factores: economías con idénticos valores de $K, h$ y $L$ pueden tener distintos productos por trabajador, si los entornos económicos en los que se utilizan dichos insumos son diferentes.

Garcia y otros (1999) analizan la forma funcional de inclusión del desarrollo institucional dentro del modelo de crecimiento de Solow, así como sus consecuencias conceptuales en lo que respecta a la moderna economía institucional, siguiendo la línea de los trabajos de Douglass North. Partiendo de la formulación de Mankiw, Romer y Weil (1992), proponen otras dos hipótesis posibles en cuanto a la influencia de la variable institucional en la producción y en la productividad de los factores económicos. La primera considera que las instituciones repercuten directamente en la productividad del capital físico, en la misma forma 
que el conocimiento influye en la productividad del trabajo. Partiendo de esta hipótesis, el capital físico, ajustado según el grado de desarrollo institucional $I$, como lo indica la ecuación [3], pasa a constituir "capital efectivo".

$$
\begin{gathered}
Y_{i}=\left(I_{i} K_{i}\right)^{\alpha} H_{i}^{\beta}\left(A_{i} L_{i}\right)^{1-\alpha-\beta}, \\
\alpha, \beta>0 \text { у } \alpha+\beta<1
\end{gathered}
$$

La segunda forma de evaluar la influencia de los cambios institucionales consiste en considerar a las instituciones como un factor de producción. De esa manera, se considera que existe un acervo de instituciones que, junto con los demás factores de producción, determina el producto agregado de la economía. De acuerdo con esta propuesta, la variable que indica el grado de desarrollo institucional se incorpora a la función de producción Cobb-Douglas elevada al exponente $\gamma$, y se multiplica por el producto de los otros factores de producción, como se indica en la ecuación [4]. La diferencia entre esta segunda hipótesis y la fórmula de Jones (2000) consiste en la idea de que las instituciones ejercen una influencia directa en la productividad media y marginal de los demás factores de producción, en la medida en que la existencia de un $\gamma$ que no sea nulo implica menores relaciones capital-producto, capital humano-producto o trabajo-producto.

$$
\begin{gathered}
Y_{t}=I_{t}^{\gamma} K_{t}^{\alpha} H_{t}^{\beta}\left(A_{t} L_{t}\right)^{1-\alpha-\beta-\gamma}, \\
\alpha, \beta, \gamma>0 \mathrm{y} \alpha+\beta+\gamma<1
\end{gathered}
$$

Garcia y otros (1999) calculan las ecuaciones de convergencia y de determinación del producto para una muestra de 67 países, utilizando una escala de satisfacción con la libertad política como variable sustitutiva del grado de desarrollo institucional. Los resultados derivados de la estimación y la comparación de los coeficientes de la variable institucional indican que la hipótesis de ajuste que define el capital efectivo tiene una mayor validez empírica.

La inclusión de las variables institucionales en los modelos de crecimiento con el propósito de analizar los efectos de las reformas económicas en América Latina se definió a partir del esquema teórico analizado más atrás. Se partió de la hipótesis de que las reformas, al eliminar restricciones y disminuir el poder discrecional, aumentaban la posibilidad de apropiarse de los derechos y reducían las distorsiones de los precios relativos, como se vio en la sección anterior, afectando tanto a la productividad de los factores como a la acumulación de capital en una economía. La hipótesis inicial que se consideró fue que las reformas influían exclusivamente en la productividad del capital físico. Aplicando esta hipótesis de capital efectivo, se replanteó la función de producción neoclásica, sustituyendo el capital físico por una variable que expresaba el factor ajustado conforme a su productividad: ${ }^{11}$

$$
Y_{t}=\left(I_{t} K_{t}\right)^{\alpha}\left(A_{t} H_{t}\right)^{1-\alpha}, \text { con } 0<\alpha<1
$$

Además de la hipótesis de capital efectivo se consideraron otras dos premisas, cada una de las cuales corresponde a una nueva especificación de la función de producción. La primera de ellas relaciona la variable institucional con la productividad del factor humano de acuerdo con los modelos de influencia del conocimiento en dicha variable: se la ha denominado hipótesis de capital humano efectivo. En este caso, se sustituye el capital humano por una variable que expresa ese factor ajustado conforme a su productividad, según se indica en la ecuación [6].

$$
Y_{t}=K_{t}^{\alpha}\left(I_{t} A_{t} H_{t}\right)^{1-\alpha}, 0<\alpha<1
$$

La segunda premisa considera el efecto de la variable institucional en la productividad total de la economía, lo que implica que la estructura institucional influye en la productividad de todos los factores, de acuerdo con lo indicado en la ecuación [7], que coincide exactamente con la especificación de Jones (2000).

$$
Y_{t}=I_{t}\left[K_{t}^{\alpha}\left(A_{t} H_{t}\right)^{1-\alpha}\right], 0<\alpha<1
$$

Considerando las mismas hipótesis del modelo de Mankiw, Romer y Weil (1992) con respecto a la acumulación y el acervo inicial de conocimiento, es posible derivar de la ecuación [5] una especificación que defina el producto por trabajador. Si se reescribe la función en forma reducida, resulta que:

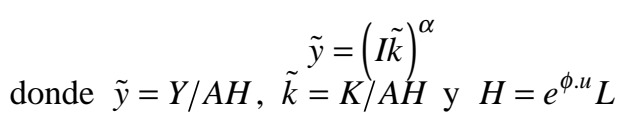

\footnotetext{
${ }^{11}$ A diferencia de Garcia y otros (1999), que adhieren a la especificación del capital humano propuesta por Mankiw, Romer y Weil (1992), aquí se optó por incluir esa variable en los modelos de Hall y Jones (1996 y 1999) y Jones (2000).
} 
Habida cuenta de que la acumulación de conocimiento está dada por $A_{t}=A_{0} \mathrm{e}^{g t}$, y partiendo de la misma hipótesis de Mankiw, Romer y Weil (1992), de que $\ln A_{0}=a+\varepsilon$, donde $a$ es una constante tecnológica y $\varepsilon$ es un impacto aleatorio específico de la economía, $\mathrm{y}$, por simplificación, $t=0$, se obtiene una especificación final que incluye la variable asociada al cambio institucional, representada por la ecuación [8]. ${ }^{12}$ Cabe destacar en esta ecuación que el coeficiente asociado al grado de desarrollo institucional es, por lo menos en términos teóricos, idéntico al coeficiente de esfuerzo de ahorro de capital físico. Eventualmente, si estos coeficientes fueran diferentes, hay evidencias que demuestran que el grado de desarrollo institucional no influiría solamente en la productividad del capital. En tal caso, es de esperar que prevalezca alguna de las otras premisas consideradas, cuyas fórmulas empíricas siguen la misma lógica de formulación que la ecuación [8] y se expresan mediante las ecuaciones [9] y [10].

$$
\begin{gathered}
\ln \left(Y_{t} / L_{t}\right)=a+\frac{\alpha}{1-\alpha} \ln I_{t}+\frac{\alpha}{1-\alpha} \ln s_{k} \\
-\frac{\alpha}{1-\alpha} \ln (n+g+d)+\phi \cdot u+\varepsilon_{t}
\end{gathered}
$$

${ }^{12}$ La ecuación de acumulación de capital de Solow (1956), en la que $s_{k}$ refleja la tasa de ahorro, $n$ el índice de crecimiento demográfico, $g$ el nivel de innovación tecnológica y $d$ el ritmo de depreciación, también puede reescribirse en forma reducida, como se indica a continuación.

$$
\dot{\tilde{k}}=s_{k} \tilde{y}-(n+g+d) \tilde{k}
$$

En el estado estacionario, la variación del acervo de capital por unidad de capital humano efectivo es nula. Se llega así al punto de equilibrio (break-even), es decir, aquél en que la inversión bruta está en equilibrio. Si en esa ecuación se sustituye la ecuación [5'], se obtiene el acervo de capital por unidad de trabajo en el estado estacionario, expresado por $\tilde{k}^{*}$. Al sustituir la expresión correspondiente a dicha variable, se llega a la ecuación del producto por unidad de capital humano efectivo en el estado estacionario, indicado por $\tilde{y} *$. Ambas ecuaciones se presentan a continuación.

$$
\tilde{k}^{*}=\left(\frac{I^{\alpha} s_{k}}{n+g+d}\right)^{\alpha / 1-\alpha} \text { y } \tilde{y}^{*}=I^{\alpha / 1-\alpha}\left(\frac{s_{k}}{n+g+d}\right)^{\alpha / 1-\alpha}
$$

Si se define $y^{*}$ como el producto por trabajador en el estado estacionario, tenemos que:

$$
y^{*}=I^{\alpha / 1-\alpha}\left(\frac{s_{k}}{n+g+d}\right)^{\alpha / 1-\alpha} A e^{\phi u}
$$

Si la ecuación anterior se plantea en forma lineal mediante la aplicación del logaritmo natural, se obtiene una nueva expresión del producto por trabajador:

$$
\ln \left(Y_{t} / L_{t}\right)=\frac{\alpha}{1-\alpha} \ln I+\frac{\alpha}{1-\alpha} \ln s_{k}-\frac{\alpha}{1-\alpha} \ln (n+g+d)+\ln A+\phi \cdot u
$$

$$
\begin{gathered}
\ln \left(Y_{t} / L_{t}\right)=a+1 \ln I_{t}+\frac{\alpha}{1-\alpha} \ln s_{k} \\
-\frac{\alpha}{1-\alpha} \ln (n+g+d)+\phi \cdot u+\varepsilon_{t} \\
\ln \left(Y_{t} / L_{t}\right)=a+\frac{1}{1-\alpha} \ln I_{t}+\frac{\alpha}{1-\alpha} \ln s_{k} \\
-\frac{\alpha}{1-\alpha} \ln (n+g+d)+\phi \cdot u+\varepsilon_{t}
\end{gathered}
$$

La investigación de los efectos de las reformas en la acumulación de capital ya tuvo como base la propia ecuación que define ese proceso, así como un corolario del modelo de Solow. Si se considera, para simplificar, que el conocimiento es constante y que no hay depreciación, la expresión correspondiente a la acumulación del factor pasa a establecer que la variación del acervo de capital por trabajador en una economía depende de dos factores: el ahorro por trabajador y la tasa de crecimiento de la fuerza laboral. El replanteo de esa ecuación se refleja en la expresión que se indica a continuación, en la que $k$ ahora representa el capital por trabajador, y $\dot{k}$ la inversión por trabajador.

$$
\dot{k}_{t}=s_{k} f\left(k_{t}\right)-n k_{t}
$$

En tal sentido, para poder influir en el proceso de acumulación de capital, las reformas deben modificar el primer término, dado que en este modelo la dinámica del mercado de trabajo está determinada por aspectos demográficos. Por lo tanto, los efectos de las reformas en el proceso de acumulación poseen, en términos teóricos, la misma naturaleza que la influencia de éstas en la generación de ahorro por trabajador dentro de la economía. Y conforme a la hipótesis de que el ahorro es igual a la inversión, sus impactos en la inversión por trabajador tienen también la misma naturaleza.

Como ya se señaló, según la formulación del modelo de Solow, se obtiene como corolario que los factores se remuneran de acuerdo con su productividad marginal. En lo que respecta al problema de maximización del beneficio de la empresa, se obtiene la relación

$$
r=\alpha \frac{Y}{K}, \text { donde } 0<\alpha<1,
$$

que define la tasa de interés a largo plazo o la rentabilidad del capital. La inversión tiene una relación negativa con esa tasa, dado que ella refleja la producti- 
vidad marginal del capital, que disminuye con el acervo del factor. A su vez, la fracción de ese producto que se destina a la acumulación no solamente se relaciona con $r$, sino también con las decisiones de las familias, que reflejan factores tales como preferencias, ciclo de vida y aspectos institucionales. Suponemos que los dos primeros factores pueden ser captados por la tasa de dependencia por edades: cuanto mayor sea esa tasa, menor será el ahorro. Por su parte, la influencia de los elementos institucionales, contexto dentro del cual se enmarcan las reformas, sigue los lineamientos analizados anteriormente. Este sencillo esquema teórico permite investigar la evolución de la inversión por trabajador y el efecto de las reformas en dicha variable, de acuerdo con la expresión siguiente:

$$
i=s_{k} f(k)=g(r, \operatorname{dep}, I)
$$

donde $i$ es la inversión por trabajador, dep la tasa de dependencia por edades, e $I$ el indicador de reformas económicas. Cabe esperar entonces que $g^{\prime}(r)<0$, $g^{\prime}($ dep $)<0$ y $g^{\prime}(I)>0$. El efecto de las reformas, si es significativo, debe ser positivo, debido a la índole tanto económica como institucional de las medidas.

\section{Reformas económicas, cambios institucionales} y crecimiento en América Latina

El análisis empírico de los efectos de las reformas durante el período transcurrido entre 1970 y 1995 se realizó sobre la base de una muestra equilibrada de 17 países latinoamericanos. El conjunto de economías se definió de acuerdo con la disponibilidad de datos referentes a las variables de reforma, en este caso los seis índices formulados por Morley, Machado y Pettinato (1999). Una vez elaborados estos indicadores para el período 1970-1975, ese aspecto también definió el intervalo de tiempo considerado. Se trabajó con seis observaciones cronológicas para cada país (1970, 1975, 1980, 1985, 1990 y 1995). De esa manera, el banco de datos abarcó un total de 102 observaciones. Las demás variables se formularon a partir de indicadores del Banco Mundial (2000) y datos de Barro y Lee (1996), actualizados a 1995. ${ }^{13}$

Como hipótesis, se consideró una tasa de depreciación constante e igual para todos los países, del $3 \%$ anual. Se partió de una tasa $g$ de $1.2 \%$, igualmente constante e idéntica para todas las economías, de acuerdo con el modelo básico de Solow. ${ }^{14}$ Sin embargo, la

\footnotetext{
${ }^{13}$ Los datos utilizados en las regresiones pueden obtenerse en Bandeira (2000), o directamente de los autores del presente artículo. ${ }^{14}$ Los valores asignados a estas dos tasas siguen los lineamientos establecidos en la bibliografía sobre el crecimiento. Véase, por ejemplo, Mankiw, Romer y Weil (1992). En el caso específico de la tasa de innovación tecnológica se optó por seguir a Piedrahita (1998), que considera que $g$ es igual a la tasa media de crecimiento del PIB real per cápita de América Latina en el período comprendido entre 1916 y 1989, establecida por el Banco Mundial.
}

hipótesis de que $\ln A_{(0)}=a+\varepsilon$ permite incorporar diferencias entre países en el nivel de conocimiento o tecnología, las que son captadas por las variables ficticias de cada país. En lo que respecta a los índices de reformas, se hizo una modificación en la variable original $I_{t}$, para tomar en cuenta que estos indicadores están limitados al intervalo comprendido entre 0 y 1 . Se consideró entonces que $I_{t}=e^{\eta}$, donde $\eta$ representa los índices de reforma (tanto el índice general como los relativos a las cinco áreas de reforma). El ahorro corresponde a la tasa media registrada en los 20 años anteriores al período analizado, y la tasa $n$ refleja el promedio entre subperíodos de 5 años.

Al principio se estimaron las especificaciones correspondientes al producto por trabajador y al producto per cápita, a pesar de que las ecuaciones teóricas del modelo tienen en cuenta concretamente el primer caso. En lo que respecta al producto per cápita, la variable $n$ pasa a representar la tasa de crecimiento demográfico, y el modelo se comporta como si todas las personas tuvieran empleo. En general, las regresiones que utilizan el producto per cápita fueron las que mostraron los mejores resultados. En consecuencia, y teniendo en cuenta los problemas asociados a la medición de la fuerza laboral en los países de la región, se definió como variable dependiente el producto per cápita.

El análisis econométrico se dividió en dos partes. En una de ellas se investigaron los efectos en la productividad total de los factores o en la productividad 
de cada factor considerado en forma individual. En la otra se analizó el impacto en la acumulación de capital. La primera estimación se basó en la ecuación [14], que se indica a continuación, donde $i=1, \ldots, 17, \mathrm{y} t=1, \ldots$, 6. De acuerdo con los valores teóricos previstos en las ecuaciones [8], [9] y [10], la evaluación del coeficiente de la variable correspondiente al cambio institucional define la hipótesis cuya probabilidad asociada es mayor: si las reformas influyen solamente en la productividad del factor físico, si afectan exclusivamente a la productividad del capital humano, o si tienen un impacto general en la productividad de la economía.

$$
\begin{gathered}
\ln \left(Y_{i, t} / L_{i, t}\right)=\beta_{0}+\beta_{1} \ln I_{i, t}+\beta_{2} \ln s_{k i, t} \\
-\beta_{3} \ln \left(n_{i, t}+g+d\right)+\beta_{4} u_{i, t}+\varepsilon_{i, t}
\end{gathered}
$$

El cuadro 1 presenta los resultados de estas regresiones. Todos los modelos se calcularon aplicando el método de mínimos cuadrados con efectos fijos. ${ }^{15}$ Los resultados preliminares de las pruebas sobre la impor- tancia de la inclusión de las variables ficticias indicaron que solamente el efecto fijo por países resultaba significativo. El hecho de que las variables ficticias cronológicas no sean significativas puede explicarse por la correlación entre esas variables, la escolaridad y los índices de reforma, dado que estos dos últimos reflejan una tendencia.

El modelo básico estimado en el cuadro 1 corresponde a la ecuación [14], sin tener en cuenta el índice de reformas. Esa variable, así como los índices específicos de cada una de las áreas, se van incorporando gradualmente a fin de comprobar sus efectos parciales. Los resultados de la primera regresión son bastante razonables y sirven como referencia para analizar el impacto de las reformas. Los coeficientes relativos al ahorro y a la escolaridad media son significativos al $5 \%$ y tienen el signo esperado. En cambio, el coeficiente asociado a la variable $n+g+d$ no es significativo. Este resultado parece estar relacionado con el hecho de que esa variable presenta un bajo grado de varianza y un alto grado de colinealidad múltiple, cap-

\begin{tabular}{|c|c|c|c|c|c|c|c|}
\hline & $\begin{array}{l}\text { Modelo } \\
\text { básico }\end{array}$ & $\begin{array}{c}\text { Indice } \\
\text { de reformas }\end{array}$ & $\begin{array}{l}\text { Apertura } \\
\text { comercial }\end{array}$ & $\begin{array}{c}\text { Reforma } \\
\text { financiera }\end{array}$ & $\begin{array}{c}\text { Liberalización de la } \\
\text { cuenta de capital }\end{array}$ & Privatización & $\begin{array}{l}\text { Reforma } \\
\text { tributaria }\end{array}$ \\
\hline \multirow{2}{*}{$\operatorname{Ln}\left(s_{K}\right)$} & 0.647 & 0.654 & 0.677 & 0.646 & 0.627 & 0.649 & 0.658 \\
\hline & $(0.112)$ & $(0.106)$ & $(0.110)$ & $(0.108)$ & $(0.111)$ & $(0.108)$ & $(0.106)$ \\
\hline \multirow[t]{2}{*}{$\operatorname{Ln}(n+g+d)$} & 0.350 & 0.427 & 0.374 & 0.407 & 0.433 & 0.319 & 0.390 \\
\hline & $(0.250)$ & $(0.239)$ & $(0.245)$ & $(0.244)$ & $(0.250)$ & $(0.242)$ & $(0.238)$ \\
\hline \multirow[t]{2}{*}{ Escolaridad (u) } & 0.072 & 0.031 & 0.042 & 0.042 & 0.061 & 0.077 & 0.028 \\
\hline & $(0.023)$ & $(0.026)$ & $(0.027)$ & $(0.026)$ & $(0.024)$ & $(0.023)$ & $(0.026)$ \\
\hline \multirow[t]{2}{*}{ Reforma (I) } & & 0.394 & 0.190 & 0.160 & 0.194 & 0.625 & 0.346 \\
\hline & & $(0.125)$ & $(0.089)$ & $(0.064)$ & $(0.103)$ & $(0.235)$ & $(0.110)$ \\
\hline $\mathrm{R}^{2}$ ajustado & 0.955 & 0.960 & 0.957 & 0.958 & 0.956 & 0.958 & 0.959 \\
\hline Error estándar medio & 0.130 & 0.124 & 0.127 & 0.126 & 0.128 & 0.125 & 0.123 \\
\hline $\mathrm{TW}-\mathrm{n} \cdot \mathrm{R}^{2}$ & 24.800 & 23.540 & 24.542 & 27.164 & 29.165 & 27.267 & 23.379 \\
\hline$\chi^{2}$ tabulado $(5 \%)$ & 37.653 & 43.773 & 43.773 & 43.773 & 43.773 & 43.773 & 43.773 \\
\hline Prueba de Hausman & 6.15 & 8.08 & 7.33 & 6.64 & 7.17 & 6.62 & 6.56 \\
\hline
\end{tabular}

\section{América Latina: Determinación del producto per cápita, 1970-1995a}

a Los números entre paréntesis son errores estándares de las estimaciones.

b La estadística $F$ calculada para la prueba del efecto fijo es igual a 2.24 . El modelo básico tiene 82 grados de autonomía y los demás modelos 81 grados.

${ }^{15}$ Siguiendo los lineamientos del análisis de Mankiw, Romer y Weil
(1992) y de Islam (1995) sobre la naturaleza del término $A_{0}$ y con-
siderando las hipótesis relativas al comportamiento de dicho térmi-
no, se optó por trabajar con el modelo de efectos fijos. La constante
tecnológica no sólo representa el conocimiento, sino también todos
los demás aspectos relacionados con la productividad de los facto-
res. En este contexto, los efectos fijos por países indican diferen- cias de productividad que, por su formulación, se correlacionan con las variables explicativas del modelo (ahorro, crecimiento demográfico y reformas). De todos modos, se aplicó la prueba de Hausman a cada modelo empírico para evaluar la posibilidad de que los términos residuales no estuvieran relacionados con el conjunto de variables explicativas, lo que implicaría una mejor estimación de los parámetros sobre la base del modelo de efectos aleatorios. 
tada por el valor elevado de la estadística VIF en todas las especificaciones.

El segundo modelo, en el que se incluyó el índice general de reformas, generó mejores resultados. Mediante una estimación realizada a partir de mínimos cuadrados con variables ficticias, se observa un ligero incremento del $\mathrm{R}^{2}$ ajustado y una reducción del error estándar de la regresión. No hay indicios de heteroescedasticidad. El coeficiente de las reformas es significativo al $5 \%$ y presenta una baja correlación con las demás variables del modelo. Otro punto que llama la atención se refiere al factor capital humano. El coeficiente estimado de esta variable, cuando se controla por efecto fijo por países y por las reformas, tiene un valor reducido y no significativo. Ello se debe también a la elevada colinealidad y la baja tolerancia del coeficiente en este segundo modelo (el viF alcanza un valor de 8,003). De esta manera, en las especificaciones del cuadro 1 se observa un cierto grado de correlación entre las variables explicativas y las variables ficticias por países, que influye en el valor estimado de los coeficientes. No obstante, este problema no requirió medidas correctivas, dado que el nivel de colinealidad múltiple parece estar dentro de márgenes aceptables.

Para analizar el impacto de cada reforma por separado, se sustituyó secuencialmente el índice general de reformas por sus componentes, lo que dio origen a los cinco modelos siguientes. Todos ellos presentan $\mathrm{R}^{2}$ ajustados superiores y errores estándares medios inferiores a los del modelo básico. Se observa una gran estabilidad en los coeficientes estimados de la variable $s_{k}$, donde el $\alpha$ implícito mantiene valores de entre 0.38 y 0.40 , en tanto que los coeficientes asociados a la variable $n+g+d$ no son significativos. En cuanto a los índices de reformas por áreas, todas las demás regresiones presentaron coeficientes significativos al $5 \%$ y fueron de signo positivo, con excepción de la regresión relativa a la liberalización de la cuenta de capital, en la que el coeficiente estimado es significativo en un $10 \%$. Ello indica que cada una de las áreas de reforma afectó positivamente el nivel del producto per cápita durante el período analizado.

Con el propósito de investigar la forma en que se produjo este efecto, se hicieron una serie de pruebas que consistieron en aplicar un conjunto de restricciones lineales a los coeficientes estimados de las variables $s_{k}$ e $I$. Estas pruebas se definieron de acuerdo con las tres especificaciones teóricas [8], [9] y [10] que establecen los valores previstos de cada uno de esos coeficientes, conforme a cada una de las hipótesis consideradas: de capital efectivo, de capital humano efectivo, o de productividad total.

Por medio de la ecuación [14] se estimaron los valores de los coeficientes asociados a cada variable, pero dicha expresión no permite determinar a priori cuál de las especificaciones es la más probable; se asignó solamente un coeficiente $\beta_{1}$ a las instituciones. Lo que permite determinar el papel de las reformas es la comparación de ese coeficiente estimado con los demás. Si mediante la prueba de aplicación de restricciones a los coeficientes no es posible refutar la hipótesis de que el coeficiente $\beta_{1}$ es igual a $\beta_{2}$, se dirá entonces que las instituciones afectan a la productividad del capital. En tal caso, los coeficientes asociados al indicador de reformas y a la tasa de ahorro serían estadísticamente iguales, por lo que resultaría válida la restricción presente en la ecuación [5].

Si no fuera posible refutar la hipótesis de que $\beta_{1}=1$, entonces la conclusión será que las instituciones responden a la hipótesis de capital humano efectivo, como propone la ecuación [9]. Este resultado es compatible con la restricción implícita en la especificación teórica formulada en la ecuación [6]. Finalmente, si no fuera posible refutar la hipótesis de que $\beta_{1}$ es igual a $1+\beta_{2}$, se puede llegar a una conclusión favorable a la tercera hipótesis, formulada en la ecuación [10]: las instituciones afectan por igual a los dos factores productivos, de manera que afectan a la productividad total de los factores. Esto sucede porque, en ese caso, el efecto de las reformas institucionales es idéntico a la suma de sus efectos parciales, tanto en el capital físico como en el capital humano efectivo, indicados respectivamente por los coeficientes de las reformas en las ecuaciones [8] y [9]. En el cuadro 2 figuran los resultados de las pruebas correspondientes a las tres hipótesis.

La primera prueba corresponde a la primera hipótesis analizada: las reformas afectaron principalmente a la productividad del capital físico. Según el cuadro 2, hay evidencias de que las reformas en general, y el proceso de privatización en particular, tuvieron un impacto significativo en la productividad de ese factor, ya que no es posible rechazar la hipótesis de que los coeficientes asociados a $s_{k}$ y a I sean iguales. En el caso de la segunda hipótesis, de capital humano efectivo, solamente la privatización parece haber tenido un efecto significativo en la productividad del factor capital humano. Como se advierte, no es posible afirmar que el impacto general de las reformas y de las cinco áreas consideradas se haya concentrado en la productividad total de las economías, de acuerdo con 
CUADRO 2

Pruebas de aplicación de restricciones lineales a los coeficientes $\beta_{1}$ y $\beta_{2}$ (Valores de la estadística t de Student) $^{\mathrm{a}}$

\begin{tabular}{lccrrr}
\hline Hipótesis & $\begin{array}{c}\text { Indice } \\
\text { de reformas }\end{array}$ & $\begin{array}{c}\text { Apertura } \\
\text { comercial }\end{array}$ & $\begin{array}{c}\text { Reforma } \\
\text { financiera }\end{array}$ & $\begin{array}{c}\text { Liberalización de } \\
\text { la cuenta de capital }\end{array}$ & $\begin{array}{c}\text { Privatización } \\
\text { tributaria }\end{array}$ \\
\hline$\beta_{1}=\beta_{2}$ & 1.598 & 3.677 & 3.859 & 2.735 & 0.094 \\
$\beta_{1}=1$ & -4.837 & -9.079 & -13.120 & -7.821 & -1.593 \\
$\beta_{1}=1+\beta_{2}$ & -7.758 & -11.224 & -11.802 & -9.051 & -3.969 \\
\hline
\end{tabular}

a Prueba bicaudal con tabulado t de $1.98($ Alfa $=5 \%)$.

la tercera hipótesis teórica. Por ende, se puede concluir que el efecto positivo de las reformas estuvo asociado al capital efectivo. O, incluso, que ese efecto en el producto de los países de la región se debió principalmente al aumento de la productividad del capital físico. La reducción o eliminación de los controles sobre los diversos mercados parece haber favorecido el uso más eficiente de ese factor.

Enseguida se estimó el efecto de las reformas en la acumulación de capital. Partiendo de un parámetro $\alpha$ de $1 / 3$, y trabajando con las series de producto y de acervo de capital, este último calculado de acuerdo con la metodología sugerida por Nehru y Dhareshwar (1993), fue posible calcular la tasa de interés a largo plazo, $r$. Luego se procedió a estimar la función que se expresa a continuación, suponiendo la siguiente especificación básica, en la que, una vez más, $i=1, \ldots, 17, \mathrm{y}$ $t=1, \ldots, 6$. Para los efectos de la estimación, se hizo una aproximación de la tasa de dependencia por edades mediante la inclusión de los adultos mayores (personas de 65 años o más). En primer lugar se verificó el índice general, y luego cada una de las reformas por separado.

$$
\ln i_{i, t}=\beta_{0}+\beta_{1} \cdot \ln r_{i, t}+\beta_{2} \cdot d e p_{i, t}+\beta_{3} . I_{i, t}+\mu_{i, t}
$$

En el cuadro 3 figuran los principales resultados y estadísticas respecto de un conjunto de especificaciones. El primer modelo corresponde a la formulación en la que la inversión per cápita es función de las tasas de interés y de la dependencia por edades. En el modelo siguiente se incorpora en forma significativa el efecto fijo por países, indicando la existencia de factores, omitidos por el modelo, que están asociados a cada economía y que afectan a la inversión en el período analizado. ${ }^{16} \mathrm{El}$ segundo modelo considera

${ }^{16}$ Las pruebas de efecto fijo indicaron que era importante incluir el efecto fijo de tiempo. En cambio, la inclusión de las variables fic- como variable explicativa el índice general de reformas, a fin de investigar el efecto del conjunto de medidas en la acumulación de capital.

El poder explicativo del modelo básico es elevado ( $\mathrm{R}^{2}$ ajustado de $\left.93.1 \%\right)$. Sin embargo, si se aplica la prueba de White no es posible desechar la hipótesis de heteroescedasticidad. Se advierte que tanto la tasa de interés como la de dependencia por edades afectan a la inversión per cápita en forma negativa. Por su parte, el coeficiente asociado a esta segunda variable no es significativo al 5\%. El modelo que incluye el índice de reformas permite obtener mejores resultados. El $\mathrm{R}^{2}$ ajustado aumenta marginalmente a medida que se reduce el error estándar de la regresión. De acuerdo con la prueba de White, no hay indicios de heteroescedasticidad. La consideración de las reformas permite ajustar los coeficientes estimados de las tasas de interés y de dependencia por edades. El coeficiente de esta última es el que registra mayor variación. Por su parte, el coeficiente de las reformas es significativo al $5 \%$ y tiene el signo esperado.

En lo que respecta a las áreas de reforma, con excepción del coeficiente estimado de la privatización, las demás son significativas al 5\%. El modelo que incorpora la privatización es incluso el que arroja los peores resultados. El $\mathrm{R}^{2}$ ajustado es el más bajo de las demás especificaciones del cuadro, mientras que el error estándar de la regresión es el más alto. Es también el único modelo que muestra indicios de heteroescedasticidad. Considerando las otras cuatro áreas de reforma, se observa claramente un efecto positivo de las medidas en la inversión per cápita durante el período analizado. Cada una de las reformas, consideradas individualmente, confirma este resultado en términos generales.

ticias cronológicas generó serios problemas de heteroescedasticidad, lo que determinó que no se tuvieran en cuenta las especificaciones que incluían esas variables. 
América Latina: Determinación de la inversión per cápita, 1970-1995a

\begin{tabular}{|c|c|c|c|c|c|c|c|}
\hline & $\begin{array}{l}\text { Modelo } \\
\text { básico }\end{array}$ & $\begin{array}{l}\text { Indice } \\
\text { de reformas }\end{array}$ & $\begin{array}{l}\text { Apertura } \\
\text { comercial }\end{array}$ & $\begin{array}{l}\text { Reforma } \\
\text { financiera }\end{array}$ & $\begin{array}{l}\text { Liberalización de la } \\
\text { cuenta de capital }\end{array}$ & Privatización & $\begin{array}{l}\text { Reforma } \\
\text { tributaria }\end{array}$ \\
\hline $\operatorname{Ln}(r)$ & $\begin{array}{l}-0.905 \\
(0.165)\end{array}$ & $\begin{array}{l}-0.785 \\
(0.157)\end{array}$ & $\begin{array}{l}-0.857 \\
(0.159)\end{array}$ & $\begin{array}{l}-0.749 \\
(0.159)\end{array}$ & $\begin{array}{l}-0.850 \\
(0.163)\end{array}$ & $\begin{array}{l}-0.939 \\
(0.174)\end{array}$ & $\begin{array}{l}-0.774 \\
(0.163)\end{array}$ \\
\hline $\operatorname{Ln}($ dep$)$ & $\begin{array}{l}-0.202 \\
(0.194)\end{array}$ & $\begin{array}{l}-0.632 \\
(0.215)\end{array}$ & $\begin{array}{l}-0.601 \\
(0.234)\end{array}$ & $\begin{array}{l}-0.547 \\
(0.203)\end{array}$ & $\begin{array}{l}-0.338 \\
(0.201)\end{array}$ & $\begin{array}{l}-0.222 \\
(0.198)\end{array}$ & $\begin{array}{l}-0.496 \\
(0.209)\end{array}$ \\
\hline Reforma (I) & & $\begin{array}{c}0.647 \\
(0.176)\end{array}$ & $\begin{array}{c}0.368 \\
(0.131)\end{array}$ & $\begin{array}{c}0.324 \\
(0.087)\end{array}$ & $\begin{array}{c}0.301 \\
(0.144)\end{array}$ & $\begin{array}{c}0.228 \\
(0.367)\end{array}$ & $\begin{array}{c}0.459 \\
(0.151)\end{array}$ \\
\hline $\mathrm{R}^{2}$ ajustado & 0.931 & 0.940 & 0.937 & 0.941 & 0.934 & 0.931 & 0.938 \\
\hline Error estándar medio & 0.186 & 0.173 & 0.179 & 0.173 & 0.182 & 0.187 & 0.178 \\
\hline $\mathrm{TW}-\mathrm{n} \cdot \mathrm{R}^{2}$ & 35.799 & 29.519 & 32.579 & 31.333 & 33.484 & 39.100 & 34.234 \\
\hline$\chi^{2}$ tabulado $(5 \%)$ & 32.671 & 37.652 & 37.652 & 37.652 & 37.652 & 37.652 & 37.652 \\
\hline $\mathrm{F}-$ efecto fijo $* *$ & 57.142 & 64.808 & 62.017 & 66.683 & 59.704 & 51.436 & 63.056 \\
\hline Prueba de Hausman & 4.49 & 15.18 & 8.30 & 8.48 & 5.43 & 6.56 & 7.15 \\
\hline
\end{tabular}

a Los números entre paréntesis son errores estándares de las estimaciones.

b La estadística $F$ calculada para la prueba del efecto fijo es igual a 2.24. El modelo básico tiene 83 grados de autonomía y los demás modelos tienen 82 .

\section{V}

\section{Consideraciones finales}

La investigación empírica de los efectos de las reformas económicas latinoamericanas permitió obtener una serie de pruebas del impacto de dichas políticas en el producto per cápita de las economías de la región, y al mismo tiempo aportó elementos útiles para el análisis de los mecanismos mediante los cuales se procesó dicho efecto. Ahora corresponde calificar esos resultados. A partir del análisis empírico de los efectos de las reformas, se puede concluir que: i) el impacto general de las reformas en el producto per cápita fue positivo; ii) considerando la productividad total y parcial de los factores, el canal principal fue el efecto positivo en la productividad del factor capital físico, y iii) la acumulación de capital respondió positivamente a las reformas, con excepción de la privatización, cuyo efecto no parece haber sido estadísticamente significativo. La tercera conclusión corrobora en cierta forma la segunda, en la medida en que, ante un aumento de la productividad marginal del capital, debería esperarse un incremento de las inversiones sostenido o más constante.

Es por esto que la recuperación del producto per cápita observada a fines del decenio de 1980 y en la primera mitad del decenio de 1990 parece estar directamente vinculada a los efectos en la productividad y la acumulación de capital. Sin embargo, debe señalarse que estos resultados, así como los que figuran en general en la bibliografía empírica sobre crecimiento económico, están condicionados a las muestras y especificaciones econométricas utilizadas, así como al conjunto de variables de control que se haya seleccionado.

La literatura empírica sobre el tema utiliza como variable dependiente la tasa de crecimiento del producto. Como ya se señaló en la introducción, esos trabajos demostraron un efecto positivo de las reformas en dicha tasa en los últimos años. La excepción fue el artículo de Escaith y Morley (2000), en el que se llega a la conclusión de que el efecto positivo de las reformas en el crecimiento fue, en la mejor de las hipótesis, indirecto. La metodología aplicada en el presente artículo permite concluir que el efecto general de las reformas en el producto per cápita de las economías fue positivo, considerando el período $1970-1995 .{ }^{17}$

\footnotetext{
17 En el apéndice se analiza el efecto de las reformas en el crecimiento de los países latinoamericanos en el período 1975-1995. Sobre la base de una ecuación teórica de convergencia condicionada, se verificó que las reformas, consideradas individualmente y en conjunto, habían tenido un efecto positivo en la tasa de crecimiento económico de la región.
} 
Como reveló el cuadro 1, todas las reformas contribuyeron a ese resultado. Asimismo, parece haber pruebas de que las reformas de hecho redujeron las distorsiones de los precios relativos (aspecto económico), y aumentaron la apropiabilidad de los derechos, principalmente bajo la forma de limitación de la discrecionalidad (aspecto institucional).

Solamente el trabajo de Barrera y Lora (1997) se ocupó de investigar los canales a través de los cuales se produjo el impacto de las reformas (aumento de la productividad o de la acumulación de capital). Esos autores llegaron a la conclusión de que el principal elemento había sido el efecto de esas medidas en la productividad total de los factores, a pesar de haberse observado una recuperación en los niveles de inversión. Las especificaciones utilizadas en la etapa empírica del presente artículo permitieron averiguar si el efecto se produjo en la productividad total o en las productividades parciales de los factores. Los resultados indicaron que el capital físico fue el factor más favorecido en términos de productividad durante el proceso de reformas. El efecto de las reformas a través del capital efectivo surge en gran medida de la evidencia vinculada a las privatizaciones. Puede decirse que esa área de reforma tuvo un claro efecto en la productividad del capital, aunque no se puede descartar su influencia a través del capital humano efectivo. Las otras cuatro reformas afectaron al producto y la inversión, pero las pruebas realizadas con los coeficientes estimados no permiten inferir que su influjo se haya ejercido a través del capital efectivo o del capital humano efectivo.

Un corolario importante de la investigación presentada en el presente artículo tiene que ver con los efectos de las reformas en la distribución del ingreso. Como ya se señaló, el impacto de las políticas en la productividad del capital físico fue mayor que en el trabajo. En otras palabras, la remuneración del capital debe de haber aumentado relativamente más que la de los demás factores. La evolución relativa de las productividades y, por lo tanto, de las remuneraciones, causada por las reformas, puede haber favorecido en cierta medida la concentración de ingresos. Morley (2000), que utiliza el mismo conjunto de seis índices de reformas económicas para evaluar el efecto del crecimiento y de las reformas en la distribución del ingreso en América Latina, encuentra indicios de que las reformas tuvieron, en general, un efecto regresivo en dicha distribución, aunque sostiene que ese impacto tuvo poca importancia en términos estadísticos.

Paralelamente a la evidencia presentada por dicho autor, hay un segundo estudio cuyas conclusiones parecen confirmar las consecuencias distributivas de las reformas. Behrman, Birdsall y Székely (2000) exploran la relación existente entre la implementación de las reformas económicas y las diferencias de salarios en 18 economías latinoamericanas en el período 19801998 (como medidas de las reformas utilizan los mismos índices que Morley, Machado y Pettinato.) Del estudio citado pueden extraerse importantes conclusiones. En primer lugar, los autores encuentran pruebas de que las diferencias de salarios entre los trabajadores con educación superior y los trabajadores con educación primaria y secundaria aumentaron considerablemente, particularmente durante el decenio de 1990. En cuanto al impacto de las reformas, llegan a la conclusión de que, en promedio, las medidas tuvieron un profundo efecto positivo en esas diferencias, con una tendencia decreciente a lo largo del tiempo. También investigan los efectos en el nivel de los salarios: los resultados — si bien son preliminares, según los autores- sugieren que las reformas tuvieron un impacto positivo en el nivel salarial. En suma, dicho estudio indica que, tomando como punto de partida el año 1980, las medidas afectaron tanto al nivel (el promedio) como a la diferencia (la varianza) de los salarios.

Los resultados empíricos y las implicaciones teóricas del presente artículo apuntan en la misma dirección. El efecto positivo de las reformas en la productividad del capital humano, aun cuando no haya sido integral, es una prueba de que el nivel de remuneración del factor registró algún incremento. A su vez, el hecho de que los aumentos de la productividad se hayan concentrado en el factor capital indica que las reformas deben haber afectado negativamente a la distribución del ingreso, en el mismo sentido que el aumento de la diferencia de salarios observada en el estudio antes mencionado. 
APENDICE

\section{La ecuación de convergencia condicionada}

Al haber afectado a la productividad y la acumulación de capital, las reformas económicas deben de estar directamente vinculadas al crecimiento del producto per cápita observado a fines del decenio de 1980 y en la primera mitad del decenio de 1990. Para evaluar ese efecto, se consideró la ecuación de convergencia condicionada de Mankiw, Romer y Weil (1992), expresando el producto, en este caso, por unidad de capital humano efectivo $\tilde{y}(t)$, como se indica en la ecuación siguiente:

$$
\ln \tilde{y}\left(t_{2}\right)-\ln \tilde{y}\left(t_{1}\right)=\left(1-e^{-\lambda \tau}\right) \ln \tilde{y}^{*}-\left(1-e^{-\lambda \tau}\right) \ln \tilde{y}\left(t_{1}\right)
$$

El producto en el estado estacionario, cuando no se impone restricción alguna a la función de producción en lo que respecta al papel de las reformas, se expresa como:

$$
\tilde{y}^{*}=I^{\gamma}\left(\frac{s_{k}}{n+g+d}\right)^{\alpha / 1-\alpha}
$$

Sustituyendo la ecuación [A.2] en la [A.1], y expresando el producto por trabajador como $y(t)$, se obtiene la ecuación siguiente, que permite evaluar el impacto global de las reformas económicas en la tasa de crecimiento de los países latinoamericanos.

$$
\begin{gathered}
\ln y\left(t_{2}\right)-\ln y\left(t_{1}\right)=\left(1-e^{-\lambda \tau}\right) \gamma \cdot I+\left(1-e^{-\lambda \tau}\right) \\
\cdot \frac{\alpha}{1-\alpha} \ln \left(s_{k}\right)-\left(1-e^{-\lambda \tau}\right) \cdot \frac{\alpha}{1-\alpha} \ln (n+g+d) \\
\quad+\left(1-e^{-\lambda \tau}\right) \cdot \phi \cdot u-\left(1-e^{-\lambda \tau}\right) \cdot \ln y\left(t_{1}\right) \\
\quad+\left(1-e^{-\lambda \tau}\right) \cdot \ln A_{(0)}+g\left(t_{2}-e^{-\lambda \tau} t_{1}\right)
\end{gathered}
$$

De acuerdo con esta fórmula, la tasa de crecimiento estaría asociada positivamente al grado de reforma: los países que hayan experimentado un mayor número de reformas debieran mostrar tasas más elevadas cuando se encuentren en un proceso de transición. La investigación econométrica se basó en un conjunto de 17 países latinoamericanos, pero se limitó al período 1975-1995, por razones de disponibilidad de datos. La especificación del conjunto, en la que $i=1, \ldots, 17$, y $t=1, \ldots, 5$, se basó en la expresión [A.4], la cual se deriva directamente de la ecuación [A.3].

$$
\begin{gathered}
\Delta \ln y(t)=\beta_{0}+\beta_{1} \ln I_{i, t}+\beta_{2} \ln s_{k i, t} \\
-\beta_{3} \ln \left(n_{i, t}+g+d\right)+\beta_{4} u_{i, t}+\beta_{5} \ln y\left(t_{0}\right)_{i}+\varepsilon_{i, t}
\end{gathered}
$$

donde $\Delta \ln y(t)$ indica la diferencia de producto entre dos momentos en el tiempo, en tanto que $y\left(t_{0}\right)$ representa el nivel del producto en el período inicial del análisis.

En el cuadro A.1 figuran los principales resultados de la estimación de la especificación antes mencionada, utilizando el modelo de efectos fijos. (Según la prueba de Hausman, este modelo es el indicado para todas las especificaciones). El modelo básico, con efecto fijo pero sin reformas, tiene un poder explicativo reducido, siendo significativo el conjunto de variables ficticias. El coeficiente estimado asociado al nivel de ingreso inicial es significativo al $5 \%$ y tiene el signo esperado. Este resultado indica la vali-

\begin{tabular}{|c|c|c|c|c|c|c|c|}
\hline & $\begin{array}{l}\text { Modelo } \\
\text { básico }\end{array}$ & $\begin{array}{l}\text { Indice } \\
\text { de reformas }\end{array}$ & $\begin{array}{l}\text { Apertura } \\
\text { comercial }\end{array}$ & $\begin{array}{l}\text { Reforma } \\
\text { financiera }\end{array}$ & $\begin{array}{l}\text { Liberalización de la } \\
\text { cuenta de capital }\end{array}$ & Privatización & $\begin{array}{l}\text { Reforma } \\
\text { tributaria }\end{array}$ \\
\hline $\operatorname{Ln}\left(y_{0}\right)$ & $\begin{array}{l}-0.731 \\
(0.127)\end{array}$ & $\begin{array}{l}-0.706 \\
(0.115)\end{array}$ & $\begin{array}{l}-0.696 \\
(0122)\end{array}$ & $\begin{array}{l}-0.721 \\
(0121)\end{array}$ & -0.693 & -0.689 & -0.767 \\
\hline $\operatorname{Ln}\left(s_{K}\right)$ & $\begin{array}{c}0.219 \\
(0.163)\end{array}$ & $\begin{array}{c}0.210 \\
(0.147)\end{array}$ & $\begin{array}{c}0.222 \\
(0.156)\end{array}$ & $\begin{array}{c}0.215 \\
(0.155)\end{array}$ & $\begin{array}{c}0.170 \\
(0.149)\end{array}$ & $\begin{array}{c}0.183 \\
(0.151)\end{array}$ & $\begin{array}{c}0.251 \\
(0.152)\end{array}$ \\
\hline $\operatorname{Ln}(n+g+d)$ & $\begin{array}{c}0.590 \\
(0.269)\end{array}$ & $\begin{array}{c}0.659 \\
(0.243)\end{array}$ & $\begin{array}{c}0.585 \\
(0.257)\end{array}$ & $\begin{array}{c}0.638 \\
(0.257)\end{array}$ & $\begin{array}{c}0.777 \\
(0.250)\end{array}$ & $\begin{array}{c}0.493 \\
(0.250)\end{array}$ & $\begin{array}{c}0.632 \\
(0.251)\end{array}$ \\
\hline Escolaridad (u) & $\begin{array}{c}0.036 \\
(0.028)\end{array}$ & $\begin{array}{l}-0.025 \\
(0.030)\end{array}$ & $\begin{array}{l}-0.008 \\
(0.032)\end{array}$ & $\begin{array}{l}-0.002 \\
(0.030)\end{array}$ & $\begin{array}{l}-0.002 \\
(0.028)\end{array}$ & $\begin{array}{l}0.035 \\
(0.026)\end{array}$ & $\begin{array}{l}-0.013 \\
(0.031)\end{array}$ \\
\hline Reforma (I) & & $\begin{array}{c}0.449 \\
(0.114)\end{array}$ & $\begin{array}{c}0.231 \\
(0.089)\end{array}$ & $\begin{array}{c}0.156 \\
(0.057)\end{array}$ & $\begin{array}{c}0.372 \\
(0.100)\end{array}$ & $\begin{array}{c}0.709 \\
(0.207)\end{array}$ & $\begin{array}{c}0.355 \\
(0.110)\end{array}$ \\
\hline $\mathrm{R}^{2}$ ajustado & 0.386 & 0.500 & 0.438 & 0.443 & 0.490 & 0.474 & 0.465 \\
\hline Error estándar medio & 0.111 & 0.100 & 0.106 & 0.106 & 0.101 & 0.103 & 0.104 \\
\hline TW $-\mathrm{n} \cdot \mathrm{R}^{2}$ & 35.458 & 37.767 & 38.661 & 37.898 & 40.286 & 39.296 & 37.590 \\
\hline$\chi^{2}$ tabulado $(5 \%)$ & 43.773 & 49.800 & 49.800 & 49.800 & 49.800 & 49.800 & 49.800 \\
\hline $\mathrm{F}-$ efecto fijo ${ }^{\mathrm{b}}$ & 3.908 & 5.455 & 4.645 & 4.421 & 5.570 & 5.241 & 4.823 \\
\hline Prueba de Hausman & 45.74 & 65.39 & 55.2 & 56.78 & 70.54 & 62.94 & 61.48 \\
\hline
\end{tabular}
dez de la hipótesis de convergencia condicionada de los ingresos de los países de la región. Los coeficientes de las demás variables no parecen ser significativos, salvo el de la tasa de inversión del punto de equilibrio (break-even) $n+g+d$, que aparece con el signo inverso.

América Latina: Determinación del crecimiento del producto per cápita, 1970-1995a

a Los números entre paréntesis son errores estándares de las estimaciones.

b La estadística $F$ calculada para la prueba del efecto fijo es igual a 2.37. El modelo básico tiene 64 grados de autonomía y los demás modelos tienen 63. 
La segunda especificación del cuadro incluye el índice general de reformas como variable explicativa en el modelo con efectos fijos. Se advierte el incremento del $\mathrm{R}^{2}$ ajustado, así como la reducción del error estándar de la regresión. No hay señales del problema de heteroescedasticidad. La prueba del efecto fijo muestra la relevancia del conjunto de variables ficticias. El coeficiente asociado a las reformas aparece como significativo (al 5\%) e indica que esas medidas, en su conjunto, influyeron en el crecimiento de los países de la región durante el período analizado. Al evaluar la influencia de las demás variables, el efecto del producto inicial sigue siendo relevante, en tanto que la tasa de inversión del punto de equilibrio continúa mostrando el signo contrario al esperado.
Si se examinan las reformas individualmente, se observa que las cinco reformas consideradas aparecen como relevantes en la determinación del crecimiento de los países de la muestra. Cabe destacar asimismo el coeficiente asociado a la privatización. Su valor es bastante superior al de los demás, como en el caso de la ecuación del producto per cápita. En las cinco especificaciones, una vez más, la tasa de ahorro y la escolaridad no parecen ser relevantes. El coeficiente estimado del nivel de ingreso inicial es significativo en los cinco modelos, lo que avala la tesis de la convergencia.

(Traducido del portugués)

\section{Bibliografía}

Banco Mundial (2000): World Development Indicators 2000, Washington, D.C.

Bandeira, A. C. (2000): Reformas econômicas, mudanças institucionais e crescimento na América Latina, São Paulo, Brasil, Escola de Administraçao de Empresas da São Paulo (EAESP), Fundación Getulio Vargas, tesis de maestría.

Barrera, F. y E. Lora (1997): Una década de reformas estructurales en América Latina: el crecimiento, la productividad y la inversión ya no son como antes, IDB working papers, $\mathrm{N}^{\circ} 350$, Washington, D.C., Banco Interamericano de Desarrollo (BID).

Barro, R. J. (1991): Economic growth in a cross section of countries, Quarterly Journal of Economics, vol. 106, $\mathrm{N}^{\circ} 2$, Cambridge, Massachusetts, MIT Press.

Barro, R. y J. Lee (1996): International measures of schooling years and schooling quality, American Economic Review, vol. 86, $\mathrm{N}^{\circ} 2$, Nashville, Tennessee, American Economic Association.

Behrman, J., N. Birdsall y M. Székely (2000): Economic reform and wage differentials in Latin America, Paper and Proceedings, $V$ Annual Meeting, Rio de Janeiro, Asociación de Economía de América Latina y el Caribe (ADEALC).

BID (Banco Interamericano de Desarrollo) (1997): América Latina tras una década de reformas. Progreso económico y social. Informe 1997, Washington, D.C.

Burki, S. y G. Perry (1997): The Long March: A Reform Agenda for Latin America and the Caribbean in the Next Decade, Washington, D.C., Banco Mundial.

Campos, N. y J. Nugent (1998): Instituciones y crecimiento. ¿Puede el capital humano ser un vínculo?, Revista de la CEPAL, N 64, LC/G.2022-P, Santiago de Chile, Comisión Económica para América Latina y el Caribe (CEPAL).

Cooter, R. y T. Ulen (1988): Law and Economics, Nueva York, Harper Collins Publishers.

Easterly, W., N. Loayza y P. Montiel (1997): Has Latin America's post-reform growth been disappointing?, Journal of International Economics, vol. 43, $\mathrm{N}^{\circ} 3 / 4$, Amsterdam, Países Bajos, North-Holland Publishing Company.

Edwards, S. (1995): Crisis y reforma en América Latina, Buenos Aires, Emecé Editores.

Escaith, H. y S. Morley (2000): The Impact of Structural Reforms on Growth in Latin America and the Caribbean: An Empirical Estimation, Macroeconomía del desarrollo, № 1, Santiago de Chile, CEPAL.

Fajnzylber, P. y D. Lederman (1999): Economic Reforms and Total Factor Productivity Growth in Latin America and the Caribbean (1950-95). An Empirical Note, Policy research working papers, $\mathrm{N}^{\circ} 2114$, Washington, D.C., Banco Mundial.

Fernández-Arias, E. y P. Montiel (1997): Reform and Growth in Latin America: All Pain no Gain?, IDB working papers, $N^{\circ} 351$, Washington, D.C., BID.

Garcia, F. y otros (1999): Instituções e crescimento: a hipótese do capital-efetivo, Proceedings of XXVII Annual Meeting of
ANPEC, Belem, Brasil, Associação Nacional dos Centros de Pós-graduação em Economia (ANPEC), diciembre.

Hall, R. y C. Jones (1996): The Productivity of Nations, NBER working papers, $\mathrm{N}^{\circ} 5812$, Cambridge, Massachusetts, Oficina Nacional de Investigaciones Económicas.

- (1999): Why do some countries produce so much more output per worker than others?, Quarterly Journal of Economics, vol. 114, $\mathrm{N}^{\circ} 1$, Cambridge, Massachusetts, MIT Press.

Hirsch, W. (1988): Law and Economics: An Introductory Analysis, San Diego, Academic Press.

Hofman, A. (2000): Economic Growth and Performance in Latin America, Serie reformas económicas, $\mathrm{N}^{\circ} 54$, Santiago de Chile, CEPAL.

Islam, N. (1995): Growth empirics: A panel data approach, Quarterly Journal of Economics, vol. 110, $\mathrm{N}^{\circ}$ 4, Cambridge, Massachusetts, MIT Press.

Jones, C. (2000): Introdução à teoria do crescimento econômico, Rio de Janeiro, Editora Campus.

Lora, E. (1997): Una década de reformas estructurales en América Latina: qué se ha reformado y cómo medirlo, IDB working papers, $\mathrm{N}^{\circ} 348$, Washington, D.C., BID.

Mankiw, N., D. Romer y D. Weil (1992): A contribution to the empirics of economic growth, Quarterly Journal of Economics, vol. CVII, $\mathrm{N}^{\circ} 2$, Cambridge, Massachusetts, MIT Press.

Morley, S. (2000): Efectos del crecimiento y las reformas económicas sobre la distribución del ingreso en América Latina, Revista de la CEPAL, $\mathrm{N}^{\circ}$ 71, LC/G.2060, Santiago de Chile, CEPAL.

Morley, S., R. Machado y S. Pettinato (1999): Indexes of Structural Reforms in Latin America, Serie reformas económicas, $\mathrm{N}^{\circ} 12$, Santiago de Chile, CEPAL.

Musgrave, R. (1959): The Theory of Public Finance, Nueva York, McGraw Hill.

Nehru, V. y A. Dhareshwar (1993): A new database on physical capital stock: Sources, methodology and results, Revista de análisis económico, vol. $8, \mathrm{~N}^{\circ} 1$, Santiago de Chile, Instituto Latinoamericano de Doctrina y Estudios Sociales (ILDES).

Paunovic, I. (2000): Growth and Reforms in Latin America and the Caribbean in the 1990s, serie Reformas económicas, $\mathrm{N}^{\circ} 70$, Santiago de Chile, CEPAL.

Piedrahita, A. (1998): Crecimiento económico en la América Latina. Estudio basado en el modelo neoclásico, El trimestre económico, vol. 65, $\mathrm{N}^{\circ} 3$, México, D.F., Fondo de Cultura Económica (FCE).

Solow, R. (1956): A contribution to the theory of economic growth, Quarterly Journal of Economics, vol. LXX, $\mathrm{N}^{\circ} 1$, Cambridge, Massachusetts, MIT Press.

Stiglitz, J. y H. Uzawa (eds.) (1969): Readings in the Modern Theory of Economic Growth, Cambridge, Massachusetts, MIT Press.

Temple, J. (1999): The new growth evidence, Journal of Economic Literature, vol. 37, $\mathrm{N}^{\circ} 1$, Nashville, Tennessee, American Economic Association. 